\title{
Sobre el ser y la esencia en Zubiri
}

\section{Introducción}

La muerte de Zubiri ha dejado un gran vacío en el campo del pensamiento español especialmente en el terreno siempre difícil de la Metafísica. Pero en este caso tenemos el consuelo de poder recurrir a su obra escrita y volver a leer sus grandes aportaciones. Aquí presentamos, de una manera sintética, algunos aspectos fundamentales de su obra Sobre la esencia, que tuvo en su día incluso una importante resonancia europea, y que completamos con algunos textos decisivos sobre la trascendencia de su escrito El hombre y Dios.

\section{La esencia y la realidad}

La esencia y la existencia son dos momentos de las cosas reales. Lo único que hay son las cosas ${ }^{1}$. Se trata de entrar en lo esencial de las cosas ${ }^{2}$.

Antes del problema de la esencia y la existencia está el problema de la esencia por sí misma ${ }^{3}$. La esencia es un "momento estructural y físico de la cosa real" ". Aquí 'físico' significa "proceder de un principio intrínseco a la cosa" ${ }^{5}$. Se trata de una realidad física, físicamente real ${ }^{6}$.

"La esencia es, pues, siempre y sólo, esencia de la sustancia" 7 . Y a su vez: "Las sustancias no son sino sus inciertas y contingentes realizaciones" ${ }^{8}$.

1. X. ZubIRI, Sobre la esencia. Sociedad de Estudios y Publicaciones. Madrid 1962, 7.

2. Ib., 10 .

3. Ib., 9 .

4. Ib., 10 .

5. Ib., 11 .

6. Ib., 13.

7. Ib., 3.

8. Ib., 5 . 
La esencia es el quid de la cosa, las notas o caracteres que hacen que la cosa sea lo que es ${ }^{9}$.

\section{La esencia según Husserl}

A veces se confunde la esencia con el 'concepto', con el 'sentido' de la cosa o con su 'definición' ${ }^{10}$.

Así para Husserl la esencia es algo absoluto que no se funda en la realidad física en cuanto tal ${ }^{11}$. Para él, la esencia es el correlato intencional de la conciencia, "el 'sentido' (Sinn) de esta intención" ${ }^{12}$.

Según Husserl, "la esencia es 'la unidad eidética de un sentido' y la conciencia "la esencia de las esencias, por ser el soporte esencial de todas ellas" ${ }^{13}$.

Al reducir "la realidad a sentido, el saber empírico se ha tornado absoluto y el hecho en esencia" ${ }^{14}$, y la esencia queda separada del hecho.

Husserl no va a la realidad sino que la descoyunta y la esencia es sólo "fundamento de la posibilidad de lo real" ${ }^{15}$. Husserl va a lo absoluto pero ha perdido "lo esencial de la realidad" ${ }^{16}$.

La esencia no es fundamentalmente sentido, porque la conciencia no consiste en 'ser-intención-de' sino en ser 'actualización' de su objeto" ${ }^{17}$.

Según Zubiri: "Las esencias están realizadas 'en' las cosas, son un momento intrínseco y formal de ellas" ${ }^{18}$. Entonces "la esencia no es algo independiente de la realidad de hecho" ${ }^{19}$.

De ahí, que la esencia no es una 'cosa ideal', ni reposa sobre sí misma sino sobre la cosa real porque es la cosa real ${ }^{20}$.

Por lo tanto, la esencia es un momento intrínseco de la cosa formado por los caracteres de la cosa en los que reposa todo lo que la cosa es: "lo esencial es lo verdaderamente real de la cosa, la esencia es su verdadera realidad" ${ }^{21}$.

\footnotetext{
9. Ib., 15,17 .

10. Ib., 23.

11. Ib., 24.

12. Ib., 25.

13. Ib., 26.

14. Ib., 26.

15. Ib., 27.

16. Ib., 28.

17. Ib., 29.

18. Ib., 30.

19. Ib., 31 .

20. Ib., 31, 32.

21. Ib., 33.
} 
Y por consiguiente, la verdad de la esencia no es un concepto sino su verdad ontológica ${ }^{22}$. La esencia no es su concepto sino la realidad del concepto de la cosa, la cosa real misma ${ }^{23}$.

\section{La esencia según Hegel}

Para Hegel: "La razón lógica misma es la substancia de lo real" ${ }^{24}$. La realidad es la racionalidad, para Hegel, nos recuerda Zubiri.

Para Hegel la existencia es el ser fundamentado en la esencia ${ }^{25}$. La esencia es algo 'interno' y la existencia su manifestación ${ }^{26}$.

La idea es la verdad de la esencia. La realidad de la Idea es la nóesis noéseos o Dios ${ }^{27}$ y la realidad entera la autorrealización procesual de Dios ${ }^{28}$. La Infinitud sería en el orden de la realidad no de la idea.

El idealismo afirma que "la inteligencia infinita es no sólo la realidad absoluta y radical, sino la realidad 'físicamente' 'única' ${ }^{29}$.

\section{Esencia y realidad en la metafísica actual}

Hoy, en la metafísica, hay "una radical primacía fundante de la realidad sobre el inteligir" ${ }^{30}$. "La realidad no se apoya, pues, en objetos ideales" ${ }^{31}$.

"Lo que el pensar 'pone' no es la esencia en el ser, sino lo esencial del ser en la inteligencia" ${ }^{32}$. Al pensar, el hombre se sitúa en las cosas como realidades, no sólo como conceptos ${ }^{33}$.

La esencia no es sólo el contenido conceptual de la cosas sino:

- la "irreductible posibilidad interna de la realidad",

- un "momento intrínseco de la cosa" 34 ,

\footnotetext{
22. Ib., 34 .

23. Ib., 34 .

24. Ib., 37.

25. Ib., 42 .

26. Ib., 43.

27. Ib., 44.

28. Ib., 45 .

29. Ib., 50 .

30. Ib., 47.

31. Ib., 72.

32. Ib., 57.

33. Ib., 58.

34. Ib., 61,65 .
} 
- "porque lo primario de ella es ser un momento intrínseco y real de la cosa misma" 35 .

La función propia de la inteligencia "no es concebir sino aprender las cosas reales como reales" ${ }^{36}$.

La esencia no es el correlato del concepto, pues "lo verdaderamente entitativo es la naturaleza. Por tanto, sólo de los entes naturales hay esencia" ${ }^{37}$. "Sólo las sustancias tienen, por tanto, esencia" ${ }^{38}$. Y su esencia es la forma sustancial, para Aristóteles.

En este sentido, el eidos es parte de la cosa real pero con frecuencia eidos "es aquello que en la cosa es correlato real de la definición" " 39 . Así la esencia es lo específico (de species) "sea como momento físico, sea como unidad definida" ${ }^{40}$.

En Aristóteles el ámbito de lo esenciable es la 'naturaleza', el ente esenciado la 'sustancia' y la esencia misma su especificación ${ }^{41}$.

La clave de la esencia no es:

- la subjetividad (algo subjetivo o ideal)

- ni la sustancialidad (algo que está debajo u oculto)

- sino la sustantividad que "expresa la plenitud de la autonomía entitativa" 42.

La sustantividad es "la estructura radical de toda realidad" ${ }^{43}$.

Se trata de algo metafísico no de algo lógico ${ }^{44}$. Sólo para Hegel y el racionalismo "la esencia sería la realidad del concepto de la cosa" ${ }^{45}$.

Por tanto, para saber de la esencia hay que ir a la realidad.

\section{La esencia como momento físico estructural de la realidad}

La esencia es momento estructural físico de la realidad, formado por la unidad primaria intrínseca de sus notas reales, y sólo así es la verdad de la cosa, "la verdad de la realidad" ${ }^{46}$.
35. Ib., 73.
36. Ib., 65 .
37. Ib., 77.
38. Ib., 78.
39. Ib., 81.
40. Ib., 82 .
41. Ib., 83 .
42. Ib., 87.
43. Ib., 87.
44. Ib., 89.
45. Ib., 94.
46. Ib., 98. 
De este modo, "la esencia es la realidad verdadera" ${ }^{47}$. "Es realidad todo y sólo aquello que actúa sobre las demás cosas o sobre sí mismo en virtud, formalmente, de las notas que posee" ${ }^{48}$.

Las propiedades de la realidad, arrancan de la realidad y se fundan en ella, pero sus notas esenciales no son notas 'de' esa realidad sino la realidad misma.

Esa realidad es su propio bien, la realidad simpliciter o sea la realidad verdadera. Y su intelección es mera actualización de la realidad, inteligible en su radicalidad ${ }^{49}$.

Sin realidad no hay verdad, pero no toda realidad es comprensible, por eso la realidad es misterio previo de su verdad que nos acoge en su realidad misma.

Primero es la realidad radical misma la que es verdadera y luego se manifiesta, patentiza, como realidad inteligible. to" 50 .

La realidad es "algo insondable que las notas van poniendo al descubier-

La verdad da seguridad: "es verdad aquello de que se puede estar seguro, en que y de que se puede fiar" ${ }^{51}$.

Pero la realidad además de tener solidez y firmeza, es algo que está ahí, es efectiva, está siendo. Así la verdad es patentización, con toda su riqueza, es seguridad y constatación ${ }^{52}$.

La constitución de la realidad es la estructura física primaria de la cosa, algo estrictamente individual. notas $^{53}$.

La individualidad es la constitución real íntegra de la cosa con todas sus

La unidad modula la determinación interna de la cosa y es su auténtica constitución radical. Hay una interdependencia de notas posicionalmente interdependientes ${ }^{54}$.

Este carácter constitucional es lo que llamamos 'sustantividad" ${ }^{55} \mathrm{o}$ "estructura formal de la unidad constitucional" ${ }^{56}$.

47. Ib., 101.

48. Ib., 104.

49. Ib., 113.

50. Ib., 128 .

51. Ib., 129.

52. Ib., 132.

53. Ib., 139.

54. Ib., 146.

55. Ib., 146.

56. Ib., 164. 


\section{1.- Esencia y sustantividad}

La sustantitividad no es una realidad oculta tras las cosas. "Sustantividad es, en cambio, suficiencia en el orden constitucional" ${ }^{57}$. No es algo sub-stante sino supra-stante ${ }^{58}$.

La sustantividad es el fundamento del ser 'sujeto a' y del ser 'sujeto-de' 59 .

La individualidad pertenece a la cosa sustantiva por su propia realidad y es el supuesto de toda intimidad, determinación y definición.

"La sustantividad no es nada distinto del sistema mismo de notas constitucionales en cuanto clausurado y total" ${ }^{60}$. Ahora bien: "la autonomía y plenitud total de la sustantividad es una unidad suficiente e irreductible" ${ }^{61}$, una sustantividad individual ${ }^{62}$.

La esencia, pues, es un momento 'físico' de la cosa real, "de la realidad sustantiva en cuanto sustantiva" ${ }^{63}$. Esta es la verdadera esencia metafísica y no la conceptual, puesto que es la "parte nuclear de la cosa" ${ }^{64}$, es su fuerza activa, lo que reúne y define sus propiedades fundamentales. Es como el jugo vital, la savia, el elixir de las cosas mismas en toda su coherencia...

\section{Esencia, constitución y hechos}

La esencia no es universal sino individual. "La esencia no es esencia de las cosas según su consideración absoluta, sino según la función que estas notas desempeñan en la cosa real" 65 .

"La esencia es esencia por una función que físicamente desempeña en la realidad individual" 66 .

$\mathrm{Y}$ es un conjunto de notas que tiene una función constitucional que concierne a la sustantividad "esto es, a la suficiencia constitucional de algo" ${ }^{67}$.

"La sustantividad, digo, es el sistema clausurado y total de notas constitucionales" 68 .

57. Ib., 157.

58. Ib., 159.

59. Ib., 160.

60. Ib., 163.

61. Ib., 166.

62. Ib., 174.

63. Ib., 176.

64. Ib., 178.

65. Ib., 183.

66. Ib., 185.

67. Ib., 186.

68. Ib., 187. 
Constitución tiene aquí un sentido estricto: "es el sistema de notas que determinan el modo intrínseco y propio de ser algo física e irreductiblemente uno, esto es, sustantivo" ${ }^{69}$.

La esencia es lo que constituye la sustantividad en cuanto tal, esto es "la realidad simpliciter de algo. Realidad simpliciter no es sino la esencia como sistema de notas constitutivas" 70 .

Las notas esenciales son el 'momento último' y 'fundante' de la realidad.

A la realidad aprendida se le suele llamar hecho, pero este es sólo un modo de ver la realidad ${ }^{71}$.

"La realidad como realización de lo potencial es hecho" ${ }^{72}$. La realidad en cuanto previamente dada, es la 'condición metafísica' de la realidad ${ }^{73}$.

La realidad creada es de condición contingente y posible ${ }^{74}$. "Necesidad, contingencia (en sus diversos modos) y libertad, son tres condiciones metafísicas de lo real" ${ }^{75}$. Lo absoluto como condición metafísica de lo real es autosuficiente, la autosuficiencia sustantiva constitucional ${ }^{76}$. Es realidad y nada más.

En ese sentido la esencia es absoluta o puramente factual: "La ultimidad estructural del mundo es pura factualidad esencial" ${ }^{77}$. Por eso al conocer el mundo y organizarlo hay que hacerlo conforme a su esencia, como el buen cocinero trincha el pollo por sus junturas naturales como ya había observado Platón.

Lo físico considerado como estructura formal y última de la realidad en cuanto tal es término del saber metafísico ${ }^{78}$.

La esencia es "el sistema físico de las notas constitutivas de la realidad sustantiva" ${ }^{79}$.

$\mathrm{Y}$ es esencialmente uno, con unidad primaria, 'constitutivamente respectiva' $^{80}$.

"La unidad esencial de la esencia constitutiva es, ciertamente una unidad física, pero no es una unidad ni de concentración ni eidética: es una unidad de coherencia" ${ }^{81}$. Y esto es así en cada cosa.

69. Ib., 190.

70. Ib., 193.

71. Ib., 196.

72. Ib., 204.

73. Ib., 199.

74. Ib., 200.

75. Ib., 204.

76. Ib., 207.

77. Ib., 209.

78. Ib., 276.

79. Ib., 280.

80. Ib., 288 .

81. Ib., 305 


\section{Esencia, individualidad y sistema}

"La esencia es formalmente individual en sentido estricto" ${ }^{82}$. Y sus notas son intraindividuales. Pero conviene observar que la esencia quidditativa es tan sólo un momento de la esencia constitutiva ${ }^{83}$.

Las notas de la esencia son constitutivamente inalterables. "Ir contra la esencia no es un contrasentido, sino una 'contra-realidad'; es la destrucción física de la realidad sustantiva" ${ }^{84}$.

La esencia constitutiva es 'últimidad de mismidad'. Es la misma y nunca la misma. "La esencia determina el tipo de actividades y pasividades que 'puede' poseer la realidad sustantiva" ${ }^{85}$.

Confundir lo genérico con lo general y lo específico con lo especial es lo que lleva a confundir especie y clase ${ }^{86}$.

La especie verdadera emerge de un phylum o esquema constitutivo genéticamente trasmitido ${ }^{87}$. Pero el conocimiento de una especie es siempre 'aproximado y parcial' ${ }^{88}$.

"Entitativa y formalmente, la esencia es ultimidad constitutiva individual" ${ }^{89}$, sin referencia a otras realidades. Su nueva generación es evolución. Mas la generación es un fenómeno de sustantividad no de sustancialidad ${ }^{90}$. Por lo demás, toda definición supone la unidad previa.

"La esencia es sistema por sí misma; el resto de la sustantividad es sistema $a b$ alio, ab essentia" ${ }^{91}$. En la esencia hay 'necesidad sistemática'. Es unidad, no azar, unidad absoluta no de inherencia. Es una coherencia de la realidad en cuanto real.

\section{Esencia, sustantividad y orden trascendental}

La sustantividad "no tiene carácter de sujeto, sino de sistema, y su razón formal es la suficiencia constitucional" ${ }^{92}$.

82. Ib., 213

83. Ib., 222

84. Ib., 249

85. Ib., 272

86. Ib., 232

87. Ib., 236, 244

88. Ib., 246

89. Ib., 248

90. Ib., 313

91. Ib., 267

92. Ib., 295 
La esencia es formalmente momento de la sustantividad y sus notas tienen carácter de sistema o subsistema fundamental ${ }^{93}$.

La sustancialidad es un momento de la sustantividad pero ésta tiene prioridad metafísica sobre aquella ${ }^{94}$.

La filosofía llamó a la unidad, al bien y a la verdad propiedades trascendentales que conciernen a la realidad en cuanto tal ${ }^{95}$.

Por la unidad, cada nota reclama las demás. La unidad es exigencia de coherencia pues toda nota es respectiva con las demás por su unidad esencial o sistema intrínseco ${ }^{96}$.

La esencia no es talidad, captada en las ciencias particulares, aunque la unidad esencial sea autotalidad ${ }^{97}$.

"La unidad esencial en cuanto unidad es una primaria unidad de talidad" 98. Y es una unidad primaria clausurada y cíclica que hace a lo real justamente tal ${ }^{99}$.

La esencia no pertenece al orden de la talidad sino "al orden de la realidad en cuanto realidad" ${ }^{100}$, que es un orden trascendental.

A su vez el yo es una realidad que va hacia el no-yo, hacia lo trascendental. El yo por ser yo se remite a la realidad. "El 'yo' se inscribe dentro del orden real" 101 .

Aprender la realidad no es, sin más, definirla ${ }^{102}$ ni relacionarla sino captar su 'sistema intrínsecamente constructo de notas'. Y esa es su índole metafísica.

Ahora bien, "el orden trascendental no es orden de la realidad en cuanto verdad, sino que es el orden de la realidad in tanto que realidad" ${ }^{103}$.

'Lo trascendental es el orden de lo real'. Lo trascendental no es lo real como verdadero sino lo real en cuanto real.

Así lo importante del ser es el ser sustantivo, que en relación a la vida intelectiva es verum, en relación a a la vida apetitiva es bonum.

Todo bonum se funda en el verum y éste en el unum. Este es la positiva unidad indivisa ${ }^{104}$. La unidad es actualidad actualizante y esenciante...

93. Ib., 295.

94. Ib., 296.

95. Ib., 327.

96. Ib., $331,335,355$.

97. Ib., 361 .

98. Ib., 369.

99. Ib., 370 .

100. Ib., 372 .

101. Ib., 381.

102. Ib., 352.

103. Ib., 381.

104. Ib., 420. 
Además, en cada cosa hay respectividad sin que esta sea nada realmente distinto de la cosa real ${ }^{105}$. La respectividad en el orden de la realidad en cuanto tal es lo que llamamos mundo ${ }^{106}$.

El mundo es respectivo a Dios pero Dios no lo es al mundo ${ }^{107}$.

\section{La esencia, la realidad de suyo y el ser}

La realidad es previa a la verdad y a la objetividad. 'Si se me permite la expresión', realidad es 'extra-animidad', dice Zubiri.

Pero la realidad no es sólo extra-animidad, pues la cosa es algo 'de suyo' ${ }^{108}$. "Realidad es ese 'de suyo' de las cosas" ${ }^{109}$.

$\mathrm{El}$ 'de suyo' no es a se, ni per se, sino ex se, tomada la cosa aquí y ahora, independientemente de su fundamento ${ }^{110}$.

Primero es la cosa real y luego es la esencia y la existencia que son acepciones distintas de un misma realidad ${ }^{111}$. La realidad es tanto esencia como existencia.

La realidad tiene un cierto carácter érgico, activo. "Y, en su virtud, se considera este carácter érgico como un carácter de lo que es real" ${ }^{112}$. Pero este carácter érgico no es lo fundamental de la realidad.

La realidad es algo irreductible que puede explicarse diciendo que es algo 'de suyo'. "Las cosas empiezan y terminan donde empieza y termina el "de suyo"" 113.

La realidad no es un modo excelente de 'ser' sino que es anterior al 'ser' y el ser es una actualidad de lo ya real en y por sí mismo ${ }^{114}$.

La impresión de realidad nos remite a lo real que es la formalidad propia de lo entendido. La inteligencia sentiente nos remite a lo real, pues no es la facultad del 'ser' sino de la 'realidad' ${ }^{115}$.

El origen de la realidad es un 'venir al mundo'. "Lo primero es llegar a la realidad, lo segundo es llegar a ser. Y esto último es lo que siempre se expresa con la metáfora del fóos, de la luz" ${ }^{116}$, pues se trata de un 'alumbramiento'.

\footnotetext{
105. Ib., 427.

106. Ib., 427.

107. Ib., 431.

108. Ib., 390, 391, 394.

109. Ib., 395.

110. Ib., 399.

111. Ib., 400.

112. Ib., 401.

113. Ib., 413.

114. Ib., 410.

115. Ib., 416.

116. Ib., 433.
} 
Por lo demás, "el ser mismo es la actualidad de lo real como momento del mundo" ${ }^{117}$. 'Ser es, pues, la actualidad mundana de lo real'. Ser es là actualidad ulterior de la realidad. "El ser no es un ente, sino que es siempre y sólo ser del ente" ${ }^{118}$.

El ser del hombre consiste en que el ser está ahí ${ }^{119}$. El Da-sein es el tiempo o exposición del ser. El $D a$ es su patencia misma ${ }^{120}$, que no es mostrarse sino 'darse' ${ }^{121}$.

El ser es la 'luminidad misma', el splendor de la realidad ${ }^{122}$. "La realidad como 'de suyo' (brillo) es el fundamento de la realidad como iluminadora (luz); y la actualidad de la realidad en ese mundo es el ser" ${ }^{123}$.

Por tanto, el hombre no es 'pastor del ser' sino "animal de realidades" ${ }^{124}$.

\subsection{El ser y la esencia, caducidad y poder}

La realidad es lo trascendental ${ }^{125}$ y algo de 'suyo', aunque limitado o caduco: 'La realidad es intrínsecamente caduca; la función transcendental de esta caducidad es la limitación'.

El fundamento de nuestra dualidad es la caducidad de lo real. Y la caducidad es intrínseca a la realidad misma.

Lo real es de suyo como un 'constructo de realidad' por eso se halla interna y trascendentalmente estructurado como unidad trascendental ${ }^{126}$.

De ahí que se pertenece a sí mismo, tiene perfección propia y duradera, solidez y estabilidad, con un ser de suyo en sí pero abierto.

Así la realidad sería un sistema de poderes o poderosidades ${ }^{127}$, es la fuerza de lo real, no una fuerza física, sino, simplemente, la misma 'fuerza de las cosas'.

Creer que el poder es lo único decisivo en las cosas, sería primitivismo ${ }^{128}$. Pero ignorar el poder de la realidad sería una ingenuidad, según Ortega.

117. Ib., 434.

118. Ib., 439.

119. Ib., 439.

120. Ib., 440 .

121. Ib., 445 .

122. Ib., 448.

123. Ib., 449.

124. Ib., 452.

125. Ib., 463.

126. Ib., 481.

127. Ib., 510 .

128. Ib., 511. 
La sustantividad es el sistema de notas dotado de autosuficiencia en orden a la constitución y la esencia, "es el sistema fundante" ${ }^{129}$. Pero la esencia no es una vis sino pura estructura...

Un organismo tiene sustancias, pero no es una sustancia sino una sustantividad. "En definitiva, como principio, la esencia es principio estructural de la sustantividad" ${ }^{130}$.

"Esencia es absolutamente idéntico a realidad" ${ }^{131}$. Y es anterior al dualismo esencia-existencia ${ }^{132}$.

Por eso tampoco hay distinción física entre esencia y existencia 'tamquam res et res' como decía Egidio Romano ${ }^{133}$.

"La esencia es un momento de la sustantividad, aquel momento según el cual la cosa es res" 134 .

La esencia no es sustancia, ni segunda ni primera...

\section{La religación del hombre a la realidad y al ser: la religión como radi- cación del hombre}

Dios no es propiamente un ser sino un 'super-ser', o realidad suprema.

Para Zubiri, el hombre es un animal de realidades ${ }^{135} \mathrm{y}$, de suyo, metafísico, absoluto, realidad en camino. Es un yo, pero comunal, prospectivo, histórico, que debe estar a la altura de los tiempos ${ }^{136}$.

Para Zubiri el problema de Dios, el problema del hombre y el problema del mundo es un solo y mismo problema.

Olvidar el problema de Dios es olvidarse el hombre de sí mismo, deshacerse de su problema, desentenderse de sí mismo y perder su propia memoria y huir de la realidad.

Para Zubiri, el hombre es su misma vida como Inteligencia Sentiente.

El hombre es actor de su vida pero siempre en un contexto, por ello tiene que elegir y realizarse, poseerse a sí mismo desde la realidad que le impele, pues vive desde, en y por la realidad ${ }^{137}$.

129. Ib., 511, 512 .

130. Ib., 517.

131. Ib., 458 .

132. Ib., 459.

133. Ib., 471.

134. Ib., 479.

135. X. ZUBIRI, El hombre y Dios. Madrid 1984, 47.

136. Ib., 73, 372.

137. Ib., 83, 373. 
Estamos fundados en la realidad, ella nos envuelve con su poder, el poder de lo real en cuanto tal ${ }^{138}$. "Es el poder que se nos presenta ante todo como el poder de lo alto, el 'altísimo"" 139 .

Se trata de un poder que rige el universo cósmico-moral; y es una fuerza sacralizante y 'perdurante' y fundante porque religa al hombre a lo real. La religación tiene un carácter experiencial de la realidad concreta y enigmática...

Esta produce en el hombre la inquietud y la búsqueda, y tiene como contrapartida la voz absoluta de la conciencia que es el fondo radical, absoluto de mi realidad, y me dice:

"Yo soy absoluto de modo relativo. Y esta relatividad es la religación. Esta religación nos remite experiencialmente al poder de la realidad, y por tanto mi propia realidad es para mí algo enigmático" ${ }^{140}$.

Entonces, si hay voluntad de verdad y voluntad de realidad, si hay auténtica vida humana, se descubre el fundamento de la realidad y de mi ser absoluto, porque, en definitiva:

"La voz de la conciencia no es sino el clamor de la realidad camino de lo absoluto" 141 .

En esta radicación y religación, la realidad del absoluto, se va apoderando de mí, pues el problema de la realidad-fundamento no nos lleva al problema de Dios sino que "es formalmente el problema de Dios" ${ }^{142}$.

La realidad misma nos conduce a 'la ultimidad de lo real que es Dios' ${ }^{143}$. Pues Él mismo nos alcanza como el poder de lo real y realidad suprema: "Dios no es ente divino; es realidad suprema" ${ }^{144}$.

\subsection{El misterio de la realidad: Dios y el hombre real}

La realidad profunda y su poder absoluto, sin ser el mundo, no está fuera del mundo, sino en las cosas mismas como determinación de su valor trascendente. Como dice Zubiri: "Dios está en las cosas, pero sin ser ellas mismas; es lo que yo entiendo por trascendencia de Dios" ${ }^{145}$.

138. Ib., 89, 373-374.

139. Ib., 90 .

140. Ib., 101.

141. Ib., 104. Subrayado nuestro.

142. Ib., 110, 377.

143. Ib., 127.

144. Ib., 131.

145. Ib., 189. 
En definitiva: "La vida es constitutivamente enigmática porque vivir es hacer mi relativo ser absoluto y éste es enigmático por serlo el poder de lo real en que se funda" ${ }^{146}$.

Así, es cada cosa real la que nos llama hacia el ser absoluto del hombre, hacia la realidad absolutamente absoluta, la realidad misma de Dios ${ }^{147}$.

El poder de lo real como posibilitante del hombre descubre para éste a Dios como su fuerza y su poder, su 'Roca' firme. Este misterio de lo real 'impele al hombre a hacerse su ser absoluto' que manifiesta a la deidad como la realidad misma de la vida y que por eso es manifestación religadora de Dios en "intimación vital" ${ }^{148}$.

Como dirían Salinas y Lorca: cada cosa tiene su misterio y la poesía -para cada cual su vida- es el camino y el encuentro con el misterio de las cosas.

El hombre es una manera finita de ser Dios. No es que Dios me haga mi vida, sino que 'hace que yo haga' mi Yo, mi ser. Así cada acto me constituye en Dios, como realitas me reificans. Por eso el hombre a veces padece como una "fatiga de lo absoluto, una especie de fatiga teologal" ${ }^{149} . .$.

Dios no es ni 'el gran ausente' de las cosas (agnosticismo) ${ }^{150}$, ni se confunde con las cosas (panteísmo), ni hay la alternativa: Dios o las cosas.

La verdadera realidad abarca Dios y las cosas, sin confusión ni división. Dios es manantial de las cosas decía Ortega, Dios es realitas fontanalis, dice Zubiri ${ }^{151}$.

Y como decía Simmel, "Dios: la más elevada realidad, fuente y desembocadura de todas las corrientes de la existencia individual que vive sobre y al mismo tiempo en todas las cosas, lo más general, y sin embargo, la posesión más propia de cada alma" ${ }^{152}$.

Así, Dios es 'constitutivamente accesible' y se deja alcanzar en "la fundamentalidad constituyente de las cosas" ${ }^{153}$.

Por eso el hombre, al hacer su yo, velis nolis, "está haciendo su Yo en Dios (ultimidad), con Dios (posibilitante) y por Dios (impelente)" ${ }^{154}$.

De este modo, al ser llevados por el poder de lo real, somos conducidos a Dios y por Dios. "El hombre, en las cosas, se entrega a lo trascendente en ellas" 155.

146. Ib., 145.

147. D. NATAL, El enigma de Ortega y la religión actual. Valladolid 1989, 64.

148. X. ZuBIRI, El hombre y Dios, 159.

149. Ib., 163.

150. Ib., 176 .

151. Ib., 177.

152 G. Simmel, De la salvación del alma, en El individuo y la libertad. Ensayos de crítica de la cultura. Barcelona 1986, 155.

153. X. ZuBiRI, El hombre y Dios, 186.

154. Ib., 182.

155. Ib., 198; 379. 
Bien entendido que demandar ayuda a Dios "es pedir a un Dios que es transcendente en mi. Acudir a Dios es acudir a mi propio fondo transcendente. Al entregarse a Dios, el hombre se entrega a lo más radicalmente suyo" ${ }^{156}$.

Pero yo no soy Dios: "Yo no soy Yo más que por la presencia formal y constitutiva de Dios en mí como realidad personal" ${ }^{157}$. Y por eso "Dios es el fundamento real de mi Yo" ${ }^{158}$.

Cuando nos desentendemos de Él, nos desentendemos del mundo y de nosotros mismos, de ahí "la fundamentalidad de Dios a diferencia de la ociosidad de Dios" ${ }^{159}$.

Por lo demás: "El hombre se ocupa de Dios pura y simplemente ocupándose con las cosas, con las demás personas" ${ }^{160}$.

El ser humano encuentra a Dios en las cosas y en la vida. "El hombre encuentra a Dios precisamente en la plenitud de su ser y de su vida" ${ }^{161}$.

El hombre se hace persona religado al poder de lo real en tanto que real y que le pone ante Dios en cuanto Dios...

Para el cristianismo, el hombre es deiforme, una manera finita de ser Dios:

"El momento de finitud de esa deiformidad es lo que, a mi manera de ver, constituye eso que llamamos 'naturaleza humana'. Dios es transcendente 'en' la persona humana, siendo esta deiformemente Dios" ${ }^{162}$.

De este modo, el hombre llega a su raíz más profunda y arraiga en su verdadera realidad. La religión es la seriedad de la vida desde la raíz ${ }^{163}$.

Entonces, la energía humana dispersa y disipada por la vanidad y la nada se religa y se pone a disposición del hombre, del mundo y de Dios.

Domingo Natal Álvarez

Estudio Teológico Agustiniano

Valladolid

156. Ib., 203, 216.

157. Ib., 352 .

158. Ib., 259; 261, 329, 349.

159. Ib, 261.

160. Ib., 333.

161. Ib., 344

162. Ib., 381.

163. J. MARÍAs, Problemas del cristianismo. Madrid 1979. 